\title{
Article \\ Reducing the Halotolerance Gap between Sensitive and Resistant Tomato by Spraying Melatonin
}

\author{
Rong Zhou ${ }^{1,2,3} \mathbb{D}^{\mathrm{D}}$, Benjian Cen ${ }^{1,2}$, Fangling Jiang ${ }^{1,2}$, Mintao Sun ${ }^{1,4}$, Junqin Wen ${ }^{1,2}$, Xue Cao ${ }^{1,5}$, Shouyao Cui ${ }^{1,2}$, \\ Lingpeng Kong ${ }^{1,2}$, Niannian Zhou ${ }^{1,2}$ and Zhen $\mathrm{Wu}^{1,2, *}$
}

1 College of Horticulture, Nanjing Agricultural University, Weigang No. 1, Nanjing 210095, China; rong.zhou@food.au.dk (R.Z.); cenbenjian@163.com (B.C.); jfl@njau.edu.cn (F.J.); sunmintao@caas.cn (M.S.); 2017204025@njau.edu.cn (J.W.); caoxue@lyu.edu.cn (X.C.); cuishouyao@163.com (S.C.); 18751968123@163.com (L.K.); 2021204031@stu.njau.edu.cn (N.Z.)

2 Key Laboratory of Horticultural Plant Biology and Germplasm Innovation in East China, Ministry of Agriculture, Nanjing 210095, China

3 Department of Food Science, Aarhus University, 8200 Aarhus, Denmark

4 The Institute of Vegetables and Flowers, Chinese Academy of Agricultural Sciences, Zhongguancun South Str., Haidian District, Beijing 100081, China

5 College of Agriculture and Forestry Science, Linyi University, Middle of Shuangling Road, Lanshan District, Linyi 276012, China

* Correspondence: wzh@njau.edu.cn; Tel.: +86-25-8439-9083; Fax: +86-25-8439-6251

check for updates

Citation: Zhou, R.; Cen, B.; Jiang, F.; Sun, M.; Wen, J.; Cao, X.; Cui, S.; Kong, L.; Zhou, N.; Wu, Z. Reducing the Halotolerance Gap between Sensitive and Resistant Tomato by Spraying Melatonin. Agronomy 2022, 12, 84. https://doi.org/10.3390/ agronomy12010084

Academic Editor: Byoung Ryong Jeong

Received: 30 November 2021 Accepted: 28 December 2021 Published: 30 December 2021

Publisher's Note: MDPI stays neutral with regard to jurisdictional claims in published maps and institutional affiliations.

Copyright: (c) 2021 by the authors Licensee MDPI, Basel, Switzerland. This article is an open access article distributed under the terms and conditions of the Creative Commons Attribution (CC BY) license (https:// creativecommons.org/licenses/by/ $4.0 /)$.

\begin{abstract}
Salt stress is one of the primary abiotic stresses that negatively affects agricultural production. Melatonin, as a useful hormone in plants, has been shown to play positive roles in crop improvement to abiotic stress conditions. However, it remains unclear whether spraying melatonin could reduce the halotolerance gap between tomato genotypes with different salt sensitivities. Here, plant growth, $\mathrm{H}_{2} \mathrm{O}_{2}$ content, electrolyte leakage, antioxidant system, gas exchange, pigment content, and chloroplast ultrastructure of salt sensitive genotype (SG) and resistant genotype (RG) at CK (control), M (spraying melatonin), S (salt), and SM (spraying melatonin under salt stress) were investigated. The results showed that the weight, height, and stem diameter of the plant at SM from both genotypes significantly increased compared with $\mathrm{S}$. The plant undergoing SM from both genotypes showed significantly decreased $\mathrm{H}_{2} \mathrm{O}_{2}$ but increased activity of SOD, APX, GR, and GSH, as well as net photosynthetic rate and Fv / Fm, as compared with S. The ratio between SM and S (SM/S) of SG was significantly higher than that of RG in terms of plant height and stem diameter, whereas antioxidant parameters, $\mathrm{H}_{2} \mathrm{O}_{2}$ content, and electrolyte leakage showed no difference between RG and SG in SM/S. The SM/S of SG in terms of photosynthetic parameters and pigment content were significantly higher than that of RG. Chloroplast ultrastructure showed remarkable changes under salt stress, whereas spraying melatonin reduced the destruction of chloroplasts, especially for SG. We concluded that spraying melatonin reduces the halotolerance gap between SG and RG by photosynthesis regulation instead of the antioxidant mechanism. This indicated that the positive roles of melatonin on tomato plants at salt stress depend on the genotype sensitivity.
\end{abstract}

Keywords: tomato; melatonin; salt stress; halotolerance gap; photosynthesis; antioxidant mechanism; chloroplast ultrastructure

\section{Introduction}

Melatonin ( $N$-acetyl-5-methoxytryptamine) is a molecular compound with physiological activity and is widely studied in animals for its important roles. Since melatonin was discovered in plants by Dubbels and Hattori in 1995 [1,2], the functions of this hormone in animals and plants have been the subject of broad interest. Many studies have shown that melatonin can effectively relieve the damage caused by stress in plants and improve plant resistance [3-7]. 
Studies have found that nearly all stresses, such as salt, drought, heat, cold, and others can cause a rapid and massive upregulation of melatonin production in various plants [8-10]. Melatonin can slow the aging of leaves by reducing chlorophyll degradation [11-17]. Melatonin can also enhance stress resistance under abiotic stress by directly removing reactive oxygen species (ROS) or enhancing the antioxidant capacity of plants, such as tomato, wheat, and soybean [18-23]. In particular, exogenous melatonin relieved the repressed plant growth, decreased oxidative stress, improved AsA-GSH cycle, and maintained $\mathrm{Na}^{+} / \mathrm{K}^{+}$balance of tomato treated by $\mathrm{NaHCO}_{3}$ [18]. Through redox balance modulation, the pre-treatment of melatonin ameliorated the damage on wheat caused by cold stress $\left(5 / 2{ }^{\circ} \mathrm{C}\right.$ day/night for 3 days) [19]. Melatonin alleviated ultrastructural damage caused by water deficit by enhancing antioxidant scavenging ability from the perspective of antioxidant enzymes and nonenzymatic antioxidants [22]. Melatonin can trigger pathways such as increasing stress-related factors, activating mitogen-activated protein kinase (MAPK) signaling, and enhancing photosynthesis under stress in Arabidopsis and Bermudagrass [24]. Therefore, previous studies have extended our understanding of positively regulatory mechanisms in plants under stress conditions mediated by melatonin.

Soil salinization is one of the major stresses during agricultural production. Salt stress can suppress plant growth and reduce crop production and ultimately threaten the survival of plants by inducing osmotic and oxidative stress and ion toxicity. At present, the area of saline soils in the world is 100 million hectares [25]. The saline soil is projected to grow at a blistering $10 \%$ annual rate, mostly due to unreasonable tillage methods [26]. Salt stress is becoming an increasing threat that restricts the sustainable development of agriculture.

Tomato is one of the worldwide vegetable crops that is often threatened by salt stress during cultivation. The growth and production of tomato plants were usually inhibited by salt stress. A recent study found that exogenous melatonin improved salt resistance of tomato seedlings mainly by controlling ROS levels and enhancing photosynthesis via non-stomatal factors [27]. However, only one tomato cultivar ('Jin Peng Yi Hao') was applied, the salt sensitivity of which was unclear. At present, there are no reports about the effects of melatonin on tomato genotypes with different salt sensitivity. The question is whether spraying melatonin can reduce the halotolerance gap between salt-sensitive and salt-resistant tomato genotypes. In this study, the response of sensitive and resistant genotypes to salt treatment in the aspects of plant growth, $\mathrm{H}_{2} \mathrm{O}_{2}$ content, electrolyte leakage, antioxidant system, gas exchange, pigment content, and chloroplast ultrastructure was investigated. Our hypothesis is that the positive role of melatonin in increasing salt tolerance of tomato could be announced more in salt sensitive genotype. We will help to understand the effects of melatonin on different tomato genotypes in salinity conditions.

\section{Materials and Methods}

\subsection{Plant Material and Culturing}

One salt SG, 'LA1698', from tomato genetics resource center (TRGC) and one salt RG, 'Lemon Boy', from American markets were applied in the current experiment. All the seedlings were planted in the glasshouse of Nanjing Agricultural University. The temperature was $25-30{ }^{\circ} \mathrm{C} / 16-20^{\circ} \mathrm{C}$ (day/night). After pre-germination, the sterilized seeds were sowed into 72 aperture disks. During the growth period, the seedlings were irrigated with 1/2 Garden nutrient solution of Japan (GNSJ). When two euphylla appeared, the consistent size of seedlings was transferred to 32 aperture disks, cultured with quartz sand. Each disk was put in a plastic pallet $(6 \mathrm{~cm}$ high, $54 \mathrm{~cm}$ long, and $28 \mathrm{~cm}$ wide), and the plastic pallets were filled with $5 \mathrm{~L}$ of $1 / 2$ GNSJ (changing the nutrient solution every two days).

\subsection{Treatment of Experiment}

When the seedlings appeared with 5-6 leaves, the treatments started with ten seedlings per treatment. The treatments were as follows: (1) CK, spraying distilled water; (2) S, $200 \mathrm{mM} \mathrm{NaCl}+$ spraying distilled water; (3) M, spraying $100 \mu \mathrm{M}$ melatonin; and (4) SM, 
$200 \mathrm{mM} \mathrm{NaCl}+$ spraying $100 \mu \mathrm{M}$ melatonin. The GNSJ was irrigated every two days, and the $\mathrm{S}$ treatment was applied by irrigating the GNSJ containing $200 \mathrm{mM} \mathrm{NaCl}$. Melatonin was sprayed every two days at night ( $8 \mathrm{pm})$ since it is easy to decompose at light conditions.

\subsection{Experimental Method}

The growth indexes, including plant height, stem diameter, upper-ground fresh/dry weight, and under-ground fresh/dry weight were measured when the salt stress lasted for 10 days. After six days' salt stress, the third leaf from the top-down was used to measure other indexes. There were three biological replications except for the growth indexes, which had five replications.

Five seedlings were washed and dried onto the tissues and then used to measure plant height, stem diameter, upper-ground fresh weight, and under-ground fresh weight. All the seedlings were baked at $120^{\circ} \mathrm{C}$ for $30 \mathrm{~min}$ and then at $80^{\circ} \mathrm{C}$ until they reached a constant weight as dry weight.

The $\mathrm{H}_{2} \mathrm{O}_{2}$ in the leaf was extracted and analyzed as previously described by Alexieva et al. (2001) [28]. The electrolyte leakage was determined as previously described by Bajji et al. [29].

The SOD activity was determined using nitroblue tetrazolium (NBT) [30]. The POD activity was assayed based on the method of Muñoz-Muñoz et al. (2009) [31]. The CAT activity was measured based on a method previously described by Aebi (1984) [32]. APX activity was determined as previously described by Nakano et al. (1981) [33]. The GR activity was determined as previously described by Zhu et al. (2007) [34]. The contents of AsA and DHA were measured based on Zhang et al. (1996) [35]. The contents of GSH and GSSH were measured according to Nagalakshmi et al. (2001) [36].

The pigment parameters, including content of chlorophyll a, chlorophyll b, chlorophyll a/b, total chlorophyll, and carotenoid content, were measured based on Arnon (1949) [37].

The photosynthetic parameters including gs, intracellular $\mathrm{CO}_{2}$ concentration $(\mathrm{Ci})$, Tr and Pn were determined using Li-6400 (Li-Cor Company, Lincoln, NE, USA) on the 6th day at 9:00-11:00 a.m. after salt treatment. The setting of parameters was as follows: $800 \mu \mathrm{mol} \cdot \mathrm{m}^{-2} \cdot \mathrm{s}^{-1}$ photosynthetic photon flux density (PPFD), $380 \pm 10 \mu \mathrm{mol} \cdot \mathrm{m}^{-2} \cdot \mathrm{s}^{-1}$ environment $\mathrm{CO}_{2}$ concentration, and $25^{\circ} \mathrm{C}$ chamber temperature.

After $30 \mathrm{~min}$ of dark adaptation, the $\mathrm{Fv} / \mathrm{Fm}$ of seedlings were measured using IMAGING-PAM (WALZ, Effeltrich, Germany). Six spots of each leaf were measured, and the six results were averaged as result for each leaf. Three leaves from three seedlings per treatment were measured.

The leaves were fixed in $2.5 \%$ glutaraldehyde solution at $4{ }^{\circ} \mathrm{C}$ for $8 \mathrm{~h}$. After washing in phosphate buffer $(\mathrm{pH}=7.2)$, fixing in $1 \%$ osmic acid, and dehydration through a graded series of ethanol, the samples were infiltrated and embedded in Epon-812. After the samples were sliced using an ultramicrotome (LKB Nova, Bromma, Sweden), sections were stained with uranyl acetate and lead citrate. Afterwards, all the sections were observed and photographed using a transmission electron microscope (H-7650, Hitachi Ltd., Tokyo, Japan).

\subsection{Data Analysis}

At least, three biological replications were applied to all data analyses. Student's $t$-test was performed using SPSS 21.0 statistics. The difference of $p<0.05\left(^{*}\right)$ and $p<0.01\left(^{* *}\right)$ between treatments was considered as statistically significant difference. The significant difference shown in supplementary figures (Figures S1-S3) was compared among the four treatments (CK, S, M, and SM) within genotype.

\section{Results}

3.1. The Effect of Exogenous Melatonin on the Growth of Tomato Seedlings under Normal Conditions and Salt Stress

Compared with $\mathrm{CK}$, the fresh weight, dry weight, plant height, and stem diameter for M treatment showed no significant difference in both RG and SG (Figure S1a,b,d,e), 
except for the root shoot ratio of the two tomato genotypes, which significantly increased due to $M$ treatment (Figure S1c). Salt-treated (S) seedlings showed remarkably decreased fresh weight, dry weight, plant height, and stem diameter in both genotypes compared with CK (Figure S1a,b,d,e), except for the root-shoot ratio (Figure S1c). Compared with the $S$ treatment, all the growth indices for SM treatment on the two tomato genotypes significantly increased (Figure S1).

To further compare RG and SG after spraying melatonin under or not under salt stress, we set CK of RG and SG to 1 to eliminate genotype differences. The relative fresh weight, relative dry weight, relative plant height, and relative stem diameters of RG were significantly higher than those of SG for S treatment (Figure 1a,b,d,e). Although for SM treatment, the fresh weight, dry weight, plant height, and stem diameters of RG were also significantly higher than those of SG, the ratio of the higher decreased as compared with $S$ treatment. For example, under $S$ treatment, $R G^{\prime}$ 's relative fresh weight was 1.5 times that of SG, while under SM treatment, RG's relative fresh weight was 1.2 times that of SG; under S treatment, RG's relative dry weight was significantly higher than that of SG, while under SM treatment, RG's relative dry weight was not significantly different from that of SG. Furthermore, the ratio between SM and S (SM/S) of SG was significantly higher than that of RG in terms of relative plant height and stem diameters (Figure 1d,e).


Figure 1. Comparison of the growth indexes including relative fresh weight (a), relative dry weight (b), relative root shoot ratio (c), relative plant height $(\mathbf{d})$, and relative stem diameter (e) between salt-resistant and salt sensitive tomato seedlings under salt stress. All the indices were normalized to CK. RG: salt-resistant genotype; SG: salt-sensitive genotype; CK: $1 / 2$ garden nutrient solution of Japan (GNSJ) + spraying distilled water; M: GNSJ + spraying $100 \mu \mathrm{M}$ melatonin; S: GNSJ-NaCl (containing $200 \mathrm{mM} \mathrm{NaCl}$ ) + spraying distilled water; SM: GNSJ-NaCl (containing $200 \mathrm{mM} \mathrm{NaCl}$ ) + spraying $100 \mu \mathrm{M}$ melatonin. The asterisk indicates significant difference detected by Student's $t$-test $\left(p<0.05\right.$ marked with * and $p<0.01$ marked with $\left.{ }^{* *}\right)$. nd: no difference. Mean $\pm \mathrm{SE}$ were given $(\mathrm{n}=5$, biological replications).

3.2. The Effect of Exogenous Melatonin on the $\mathrm{H}_{2} \mathrm{O}_{2}$ Content and Electrolyte Leakage of Tomato Seedlings under Normal Conditions and Salt Stress

Compared with $\mathrm{CK}$, the $\mathrm{H}_{2} \mathrm{O}_{2}$ content and electrolyte leakage for $\mathrm{M}$ treatment showed no significant difference in both RG and SG (Figure S2a). Compared with CK, the $\mathrm{H}_{2} \mathrm{O}_{2}$ content and electrolyte leakage for $\mathrm{S}$ treatment of the two tomato genotypes all remarkably increased (Figure S2a). Compared with the $\mathrm{S}$ treatment, the $\mathrm{H}_{2} \mathrm{O}_{2}$ content and electrolyte leakage for SM treatment of the two tomato genotypes significantly decreased (Figure S2a). 
As explained above, we set the CK of RG and SG to 1 to eliminate genotype differences. The electrolyte leakage of SG was significantly higher than that of RG for S treatment, even though no difference was observed for $\mathrm{H}_{2} \mathrm{O}_{2}$ content (Figure 2a,b). As for SM treatment, the electrolyte leakage of SG was also significantly higher than that of RG, but the specific value was decreasing compared with $S$ treatment. Under $S$ treatment, SG's electrolyte leakage was 1.6 times that of RG, while under SM treatment, SG's electrolyte leakage was 1.3 times that of RG. Furthermore, there was no difference between RG and SG for electrolyte leakage in SM/S (Figure 2b).
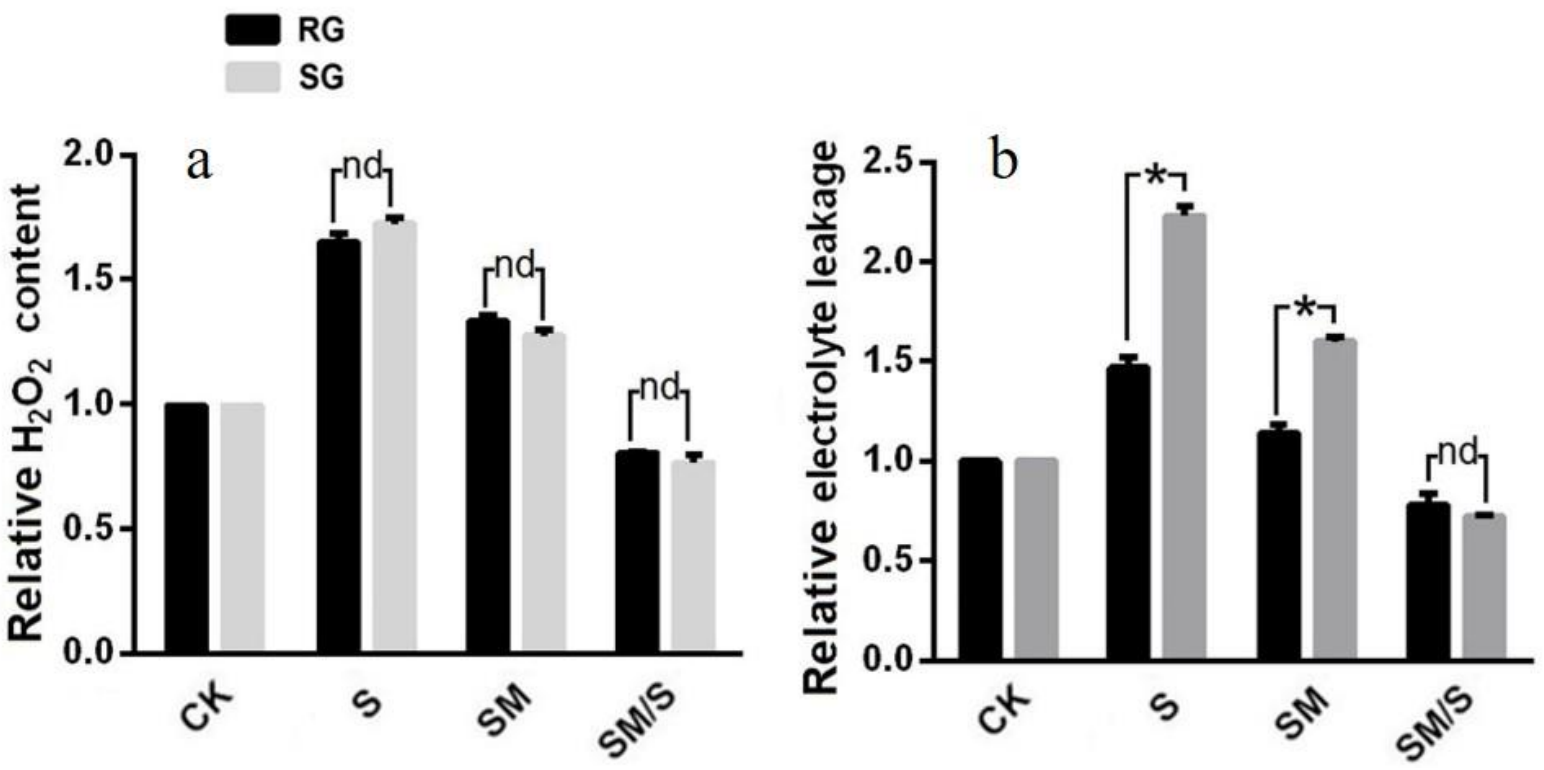

Figure 2. Relative $\mathrm{H}_{2} \mathrm{O}_{2}$ content (a) and relative electrolyte leakage (b) between salt-resistant and saltsensitive tomato seedlings under salt stress. All the indices are normalized to CK. RG: salt-resistant genotype; SG: salt-sensitive genotype; CK: 1/2 Garden nutrient solution of Japan (GNSJ) + spraying distilled water; M: GNSJ + spraying $100 \mu \mathrm{M}$ melatonin; S: GNSJ-NaCl (containing $200 \mathrm{mM} \mathrm{NaCl})+$ spraying distilled water; SM: GNSJ- $\mathrm{NaCl}$ (containing $200 \mathrm{mM} \mathrm{NaCl}$ ) + spraying $100 \mu \mathrm{M}$ melatonin. The asterisk indicates the significant difference detected by Student's $t$-test $\left(p<0.05\right.$ marked with $\left.{ }^{*}\right)$. nd: no difference. Mean $\pm S E$ were given ( $n=3$, biological replications).

\subsection{The Effect of Exogenous Melatonin on the Activity of SOD, POD, CAT, and AsA-GSH Cycles of Tomato Seedlings under Normal Conditions and Salt Stress}

There was no difference in the activity of SOD, POD, CAT, and APX, and the content of AsA between CK and M, but the GR activity, GSH content, and AsA/DHA for M, significantly increased compared with CK (Figure S2b). The SOD, POD, APX, and GR activity and GSH content significantly increased, while CAT activity, AsA/DHA, and AsA content significantly decreased under S compared with CK (Figure S2b). Compared with the $S$ treatment, almost all the antioxidant indices for SM treatment of the two tomato genotypes significantly increased, except for the activity of POD for RG and CAT for SG (Figure S2b).

Further, we compared RG and SG after spraying melatonin under or not under salt stress. The relative APX activity, relative GSH, and relative AsA content of RG were significantly higher than those of SG under S (Figure 3d,f,g). The relative GSH content of RG was significantly higher than that of SG, but the relative AsA content of SG was significantly higher than that of RG in the SM treatment (Figure 3f,g). However, there was no difference in most of these antioxidant indices between RG and SG in SM/S, except for the AsA content of SG, which was significantly higher than that of RG in SM/S (Figure 3). 
RG

SG


Figure 3. Comparison of antioxidant systems including relative SOD activity (a), relative POD activity (b), relative CAT activity (c), relative APX activity (d), relative GR activity (e), relative GSH activity (f), relative AsA activity (g), and relative AsA/DHA (h) between salt-resistant and salt-sensitive tomato seedlings under salt stress. All the indices are normalized to CK. RG: salt-resistant genotype; SG: salt-sensitive genotype; CK: 1/2 Garden nutrient solution of Japan (GNSJ) + spraying distilled water; M: GNSJ + spraying $100 \mu \mathrm{M}$ melatonin; S: GNSJ-NaCl (containing $200 \mathrm{mM} \mathrm{NaCl}$ ) + spraying distilled water; SM: GNSJ-NaCl (containing $200 \mathrm{mM} \mathrm{NaCl}$ ) + spraying $100 \mu \mathrm{M}$ melatonin. The asterisk indicates significant difference detected by Student's $t$-test $(p<0.05$ marked with * and $p<0.01$ marked with $\left.{ }^{* *}\right)$. nd: no difference. Mean \pm SE were given $(\mathrm{n}=3$, biological replications).

\subsection{The Effect of Exogenous Melatonin on the Photosynthetic Parameters of Tomato Seedlings under Normal Conditions and Salt Stress}

There was no difference in the photosynthetic parameters between CK and M, except for the transpiration rate ( $\mathrm{Tr}$ ) under normal conditions, which significantly increased after spraying melatonin (Figure S3a). All four photosynthetic parameters significantly decreased for RG and SG under S compared with CK (Figure S3a). The content of chlorophyll a, chlorophyll b, carotenoid and total chlorophyll, chlorophyll a/b, and Fv/Fm of SG significantly decreased under salt stress compared with CK (Figure S3b). Compared with the $\mathrm{S}$ treatment, intercellular $\mathrm{CO}_{2}$ concentration (Ci) of RG and SG significantly declined under SM (Figure S3a). Compared with the S treatment, Tr and net photosynthetic rate (Pn) and all pigment parameters significantly increased in SG under SM (Figure S3). 
Further, we compared RG and SG after spraying melatonin under or not under salt stress. All four relative photosynthetic parameters of RG significantly increase as compared with those of SG under S (Figure 4). The same trend was observed for the content of relative chlorophyll $\mathrm{a}$, relative chlorophyll $\mathrm{b}$, relative total chlorophyll content, and relative Fv/Fm of RG (Figure 5). However, when spraying melatonin under salt stress (SM), all four photosynthetic parameters showed no difference between RG and SG (Figure 4), while relative chlorophyll $\mathrm{a}$, relative chlorophyll $\mathrm{b}$ and relative total chlorophyll content, and relative Fv/Fm of RG still showed significantly higher than SG (Figures 5 and S4).


Figure 4. Comparison of gas exchange parameters, including relative stomatal conductance (a), relative intercellular $\mathrm{CO}_{2}$ concentration $(\mathbf{b})$, relative net photosynthetic rate $(\mathbf{c})$, and relative transpiration rate (d) between salt resistant and salt sensitive tomato seedlings under salt stress. All the indices normalized to CK. RG: salt-resistant genotype; SG: salt-sensitive genotype; CK: 1/2 Garden nutrient solution of Japan (GNSJ) + spraying distilled water; M: GNSJ + spraying $100 \mu \mathrm{M}$ melatonin; S: GNSJ-NaCl (containing $200 \mathrm{mM} \mathrm{NaCl}$ ) + spraying distilled water; SM: GNSJ-NaCl (containing 200 $\mathrm{mM} \mathrm{NaCl})+$ spraying $100 \mu \mathrm{M}$ melatonin. The asterisk indicates significant difference detected by Student's $t$-test $\left(p<0.05\right.$ marked with ${ }^{*}$ and $p<0.01$ marked with $\left.{ }^{* *}\right)$. nd: no difference. Mean $\pm \mathrm{SE}$ were given ( $\mathrm{n}=3$, biological replications).

Certainly, the Tr, Pn, chlorophyll a, chlorophyll b, carotenoid, total chlorophyll content, and chlorophyll a/b of SG in SM significantly increased compared with the $S$ treatment (Figure S3a). The chlorophyll a, chlorophyll b, carotenoid, and total chlorophyll content of SG to SM significantly increased compared with the S treatment (Figure S3b). As can be seen, the SM/S of SG was significantly higher than that of RG for relative stomatal conductance (gs), relative $\mathrm{Tr}$, and relative $\mathrm{Pn}$, as well as for relative chlorophyll a, relative chlorophyll b, and relative total chlorophyll content (Figure 5). 

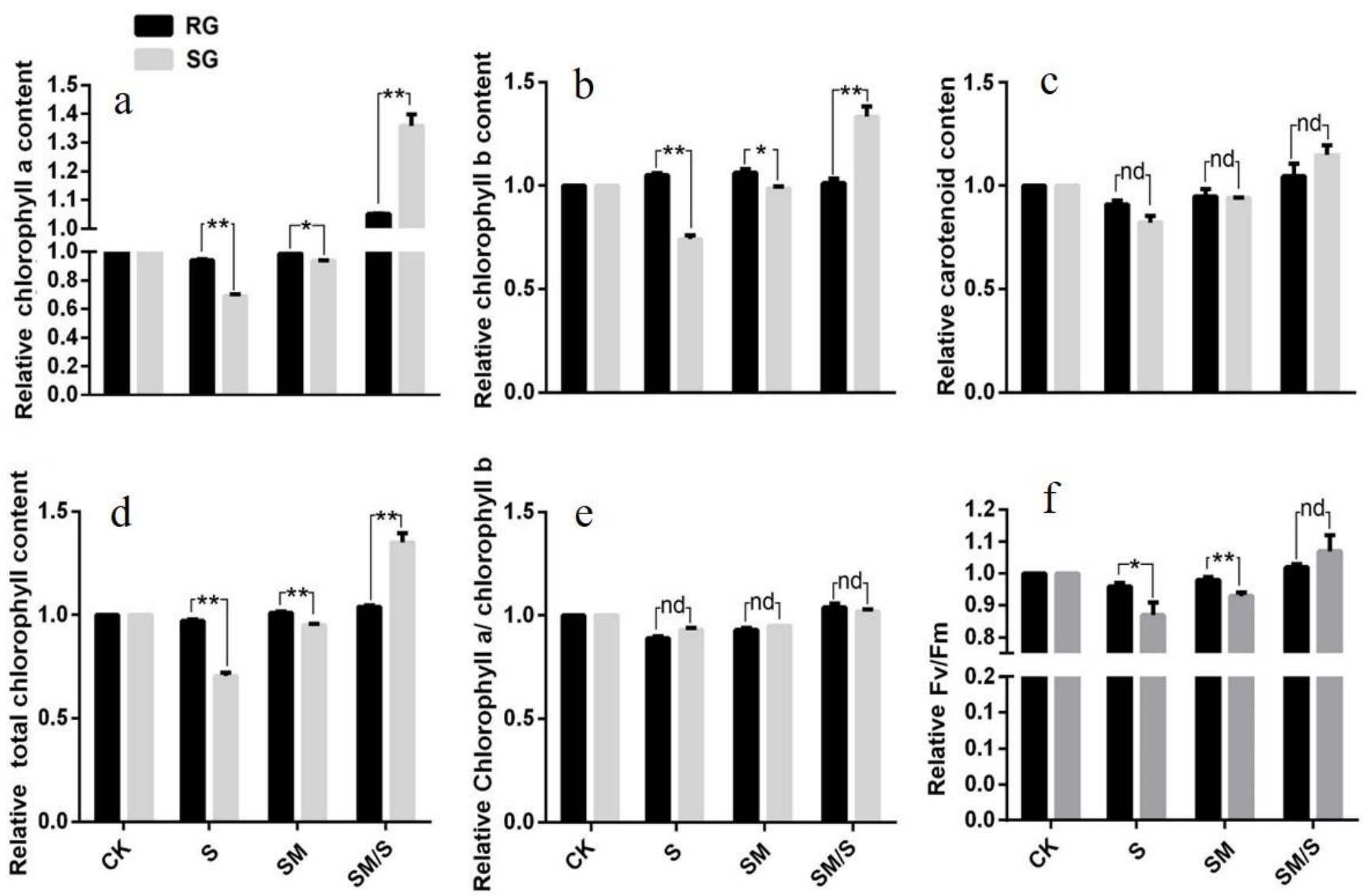

Figure 5. Comparison of pigment content and chlorophyll fluorescence, including relative chlorophyll a content $(\mathbf{a})$, relative chlorophyll b content $(\mathbf{b})$, relative carotenoid content $(\mathbf{c})$, relative total chlorophyll content (d), relative chlorophyll a/chlorophyll b (e), and Fv/Fm (f) between salt-resistant and salt-sensitive tomato seedlings under salt stress. All the indices normalized to CK. RG: salt-resistant genotype; SG: salt-sensitive genotype; CK: 1/2 Garden nutrient solution of Japan (GNSJ) + spraying distilled water; M: GNSJ + spraying $100 \mu \mathrm{M}$ melatonin; S: GNSJ-NaCl (containing $200 \mathrm{mM} \mathrm{NaCl})+$ spraying distilled water; SM: GNSJ-NaCl (containing $200 \mathrm{mM} \mathrm{NaCl}$ ) + spraying $100 \mu \mathrm{M}$ melatonin. The asterisk indicates significant difference detected by Student's $t$-test $(p<0.05$ marked with * and $p<0.01$ marked with $\left.{ }^{* *}\right)$. nd: no difference. Mean $\pm \mathrm{SE}$ were given $(\mathrm{n}=3$, biological replications).

3.5. The Effect of Exogenous Melatonin on the Ultrastructure of the Chloroplast of Tomato Leaves under Salt Stress

The effects of melatonin on the ultrastructure of the chloroplast of tomato seedlings were observed in RG and SG under S (Figure 6). Whether spraying melatonin or not, under normal conditions, there were no differences in the ultrastructure of the chloroplast, and there were many bigger oval chloroplasts whose envelopes were neighboring cell walls and could be clearly defined (Figure 6A1,B1,E1,F1). In addition, the chloroplast contained a large number of starch grains (S) (Figure 6A2,B2,E2,F2), and the layer structure of the chloroplast was clear and neatly organized (Figure 6A3,B3,E3,F3).

Under salt stress, the ultrastructure of the chloroplast showed remarkable changes (Figure 6C1-C3,G1-G3). The number of chloroplasts decreased, the volume of the chloroplasts was small and thin, and the envelope could not be identified for RG and SG (Figure 6C1,G1). In addition, the number and volume of the starch grains (S) decreased, and the number and height of the basal granule decreased (Figure 6C2,G2). The ultrastructure of the chloroplast of SG appeared to have a serious distortion under S, where the grana thylakoid (GL) and stroma thylakoid (SL) were swelling, loose and in an irregular arrangement (Figures 6G3 and S5). Compared with SG, the chloroplast was bigger, and the swelling of the GL and SL was not obvious in RG (Figures 6C1-C3,G1-G3 and S5). 


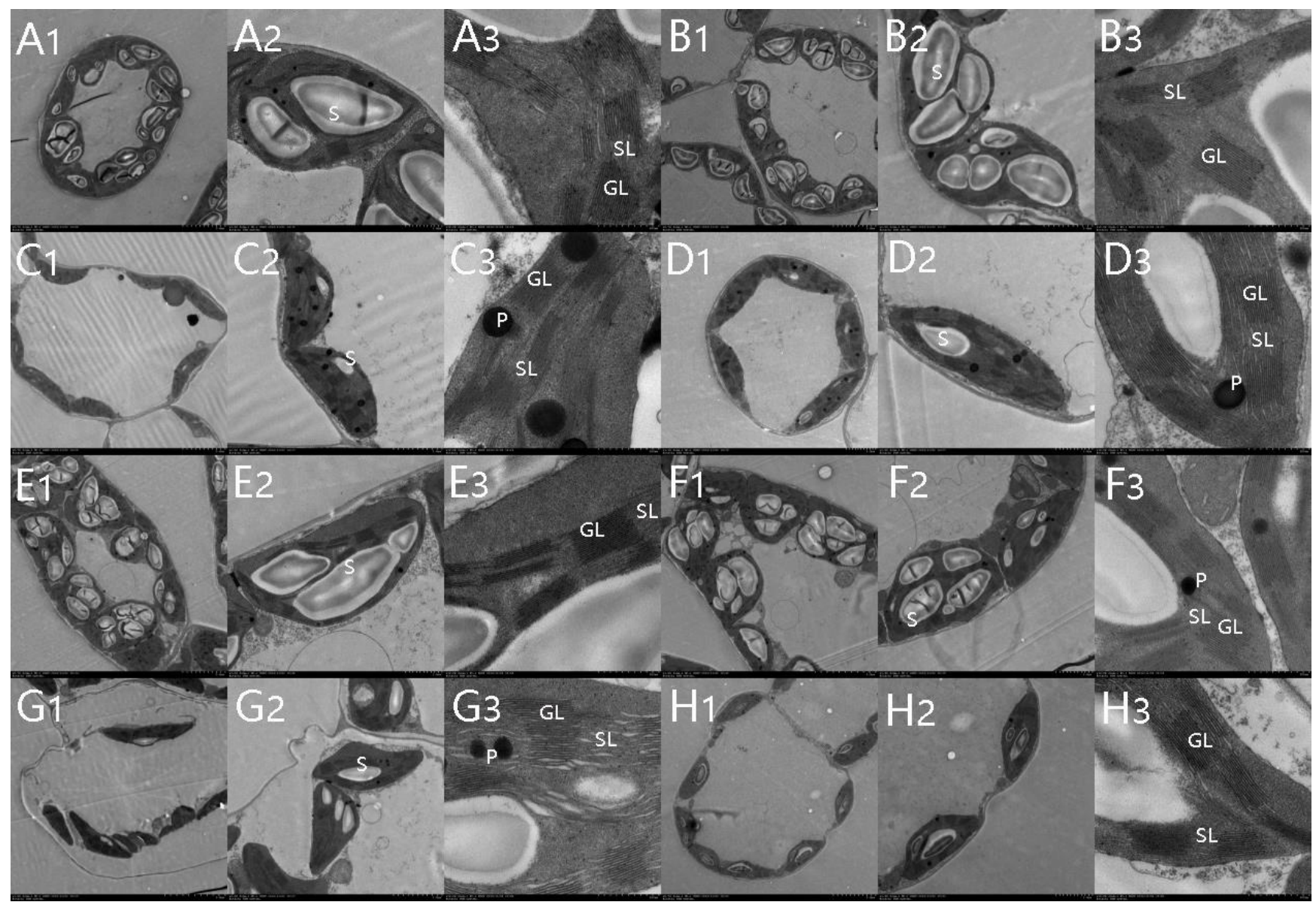

Figure 6. Comparison of chloroplast ultrastructure between salt-resistant and salt-sensitive tomato seedlings under salt stress. Salt resistance genotype: Control (A1-A3), spraying melatonin under normal condition (B1-B3), salt stress (C1-C3), spraying melatonin under salt stress (D1-D3); saltsensitive genotype: Control (E1-E3), spraying melatonin under normal conditions (F1-F3), salt stress (G1-G3), spraying melatonin under salt stress (H1-H3). P: plastoglobulus; S: starch grains; GL: grana thylakoid; SL: stroma thylakoids.

However, the volume of the chloroplast was enlarged, and the GL and SL were well aligned at SM treatment in the RG (Figures 6D1-D3 and S5). Melatonin also effectively remitted the swell of GL and SL and reduced the destruction of chloroplasts for SG (Figures 6H1-H3 and S5). In addition, there were many plastoglobules (P) in the chloroplast under salt stress in RG and SG and spraying melatonin effectively decreased the $P$ of RG and SG (Figure 6C1-C3,D1-D3,G1-G3,H1-H3). These results suggest that spraying melatonin effectively decreased the halotolerance gap in chloroplasts between RG and SG under salt stress.

\section{Discussion}

Salt stress is one of the common abiotic stresses that has an adverse influence on the growth and development of various plants including tomato [38-40]. Increasing studies have shown a beneficial role of melatonin in relieving plant growth under salt stress $[5,27,41]$. Most studies have found that melatonin can directly remove ROS and enhance the antioxidant capacity [21-23], as well as trigger molecular pathways, such as increasing stress-related factors of plants [24]. At present, there are no reports about the effects of melatonin on the tomato genotypes with different salt sensitivity. It remains unclear whether spraying melatonin can reduce the halotolerance gap between sensitive and resistant tomato genotypes. 
All five growth parameters of tomato plants under salt stress were less affected when melatonin was applied (Figure S1). Exogenous melatonin can effectively relieve the growth inhibition due to salt stress as indicated by significantly improvement in the growth index under salt stress + melatonin as compared with salt stress $[5,27,41]$, which was in accordance with our results. Moreover, we found that the SM/S of salt SG was significantly higher than that of salt RG in plant height and stem diameter (Figure 1d,e), suggesting that spraying melatonin can reduce the halotolerance gap between SG and RG. However, the question is how exogenous melatonin reduces this halotolerance gap between SG and RG. Therefore, we further studied two key systems, including antioxidant and photosynthetic systems, to explain how different genotypes respond to salt and melatonin treatment.

Salt stress can lead to excessive accumulation of ROS, resulting in oxidative damage in plants $[5,18,27]$. Accordingly, salt stress significantly increased the $\mathrm{H}_{2} \mathrm{O}_{2}$ content and electrolyte leakage in tomato (Figure S2). Previous studies indicated that exogenous melatonin can significantly enhance salt resistance by decreasing the ROS and electrolyte leakage and increasing the antioxidant indices of tomato seedlings under salt stress [18,27], which is consistent with our findings. Furthermore, the antioxidant indices $\left(\mathrm{H}_{2} \mathrm{O}_{2}\right.$ content, electrolyte leakage, and activities of antioxidant enzymes) except for AsA content showed no difference between RG and SG in SM/S (Figures 2 and 3). This suggests that the antioxidant system was not the key factor for reducing the halotolerance gap between SG and RG.

Plant photosynthesis is a complex physiological and biochemical process that can be easily affected by stress [42]. Here, the decline in photosynthesis in tomato under salt stress is due to the stomatal factor since both gs and Ci decreased, as explained by Von Caemmerer and Farquhar (1981) [43]. Melatonin can effectively relieve the decline of photosynthesis under stress conditions, including salt, heat, and cold stress $[6,10,18,19,27]$, which was in accordance with our findings in tomato under salt stress (Figure S3). Previous studies found that melatonin can significantly promote stomata opening, increase gs, and enhance photosynthesis of grape and apple plants to reduce injury caused by water deficit $[22,44]$. However, the alleviated effects of melatonin on tomato under salt were not through stomatal regulation since gs was unaffected (Figure S3). This indicated that melatonin relieved the photosynthesis of tomato under salt stress through non-stomatal factors, in accordance with Zhou et al. (2016) [27]. Most importantly, we found that, when spraying melatonin under salt stress, the SM/S of SG was significantly higher than that of RG in terms of gs, Tr, and Pn, and chlorophyll a, chlorophyll b, and total chlorophyll content (Figures 4 and 5). Furthermore, compared to the halotolerance gap between RG and SG under salt stress, the chloroplast ultrastructure showed a narrow halotolerance gap between SG and RG under salt stress after spraying melatonin (Figure 6 and Figure S5). These results suggest that exogenous melatonin reduced the halotolerance gap between SG and RG under salt stress mediated by photosynthesis regulation. High pigment content and favorable chloroplast ultrastructure, especially in salt-sensitive tomato, contributed to the maintained photosynthesis in tomato under salt stress with melatonin treatment.

This study proved that melatonin can improve salt resistance of tomato seedlings through photosynthesis regulation. Moreover, the positive effects of melatonin on tomato plants under salt stress were more pronounced in the sensitive genotype as compared with the resistant genotype. Therefore, we conclude that melatonin can reduce the halotolerance gap between sensitive and resistant tomato genotypes, mainly through regulating photosynthesis but not the antioxidant system.

Supplementary Materials: The following supporting information can be downloaded at https: / / www.mdpi.com/article/10.3390/agronomy12010084/s1, Figure S1: The effect of exogenous melatonin on the growth of tomato seedlings under salt stress, Figure S2: The effect of exogenous melatonin on $\mathrm{H}_{2} \mathrm{O}_{2}$ content, electrolyte leakage, and antioxidant system of tomato seedlings under salt stress, Figure S3: The effect of exogenous melatonin on the photosynthetic parameter of tomato seedlings under salt stress, Figure S4: The effect of exogenous melatonin on the chlorophyll fluorescence of 
tomato seedlings under salt stress, Figure S5: The effect of exogenous melatonin on the chloroplast ultrastructure of tomato seedlings under salt stress.

Author Contributions: Z.W., B.C., R.Z. and F.J. performed the experiment and analyzed the data. R.Z., M.S. and Z.W. wrote the manuscript. J.W., X.C., S.C., L.K. and N.Z. gave valuable comments to improve the manuscript. All authors have read and agreed to the published version of the manuscript.

Funding: The study was supported by National Natural Science Foundation of China (31801868) and the Priority Academic Program Development of Jiangsu Higher Education Institutions.

Institutional Review Board Statement: Not applicable.

Informed Consent Statement: Not applicable.

Data Availability Statement: Not applicable.

Conflicts of Interest: The authors confirmed that there were no conflict of interest.

\section{References}

1. Dubbels, R.; Reiter, R.; Klenke, E.; Goebel, A.; Schnakenberg, E.; Ehlers, C.; Schiwara, H.; Schloot, W. Melatonin in edible plants identified by radioimmunoassay and by high performance liquid chromatography-mass spectrometry. J. Pineal Res. 1995, 18, 28-31. [CrossRef] [PubMed]

2. Hattori, A.; Migitaka, H.; Iigo, M.; Itoh, M.; Yamamoto, K.; Ohtani-Kaneko, R.; Hara, M.; Suzuki, T.; Reiter, R.J. Identification of melatonin in plants and its effects on plasma melatonin levels and binding to melatonin receptors in vertebrates. Biochem. Mol. Biol. Int. 1995, 35, 627-634. [PubMed]

3. Beilby, M.J.; Al Khazaaly, S.; Bisson, M.A. Salinity-Induced Noise in Membrane Potential of Characeae Chara australis: Effect of Exogenous Melatonin. J. Membr. Biol. 2014, 248, 93-102. [CrossRef] [PubMed]

4. Kostopoulou, Z.; Therios, I.; Roumeliotis, E.; Kanellis, A.; Molassiotis, A. Melatonin combined with ascorbic acid provides salt adaptation in Citrus aurantium L. seedlings. Plant. Physiol. Biochem. 2015, 86, 155-165. [CrossRef] [PubMed]

5. Li, C.; Wang, P.; Wei, Z.; Liang, D.; Liu, C.; Yin, L.; Jia, D.; Fu, M.; Ma, F. The mitigation effects of exogenous melatonin on salinity-induced stress in Malus hupehensis. J. Pineal Res. 2012, 53, 298-306. [CrossRef]

6. Mukherjee, S.; David, A.; Yadav, S.; Baluška, F.; Bhatla, S.C. Salt stress-induced seedling growth inhibition coincides with differential distribution of serotonin and melatonin in sunflower seedling roots and cotyledons. Physiol. Plant. 2014, 152, 714-728. [CrossRef] [PubMed]

7. Zhang, H.-J.; Zhang, N.; Yang, R.-C.; Wang, L.; Sun, Q.-Q.; Li, D.-B.; Cao, Y.-Y.; Weeda, S.; Zhao, B.; Ren, S.; et al. Melatonin promotes seed germination under high salinity by regulating antioxidant systems, ABA and GA4 interaction in cucumber (Cucumis sativus L.). J. Pineal Res. 2014, 57, 269-279. [CrossRef]

8. Tan, D.-X.; Hardeland, R.; Manchester, L.C.; Korkmaz, A.; Ma, S.; Rosales-Corral, S.; Reiter, R.J. Functional roles of melatonin in plants, and perspectives in nutritional and agricultural science. J. Exp. Bot. 2011, 63, 577-597. [CrossRef]

9. Reiter, R.J.; Tan, D.-X.; Zhou, Z.; Cruz, M.H.C.; Fuentes-Broto, L.; Galano, A. Phytomelatonin: Assisting Plants to Survive and Thrive. Molecules 2015, 20, 7396-7437. [CrossRef] [PubMed]

10. Shi, H.; Tan, D.-X.; Reiter, R.J.; Ye, T.; Yang, F.; Chan, Z. Melatonin induces class A1 heat-shock factors (HSFA1s) and their possible involvement of thermotolerance in Arabidopsis. J. Pineal Res. 2015, 58, 335-342. [CrossRef] [PubMed]

11. Arnao, M.B.; Hernández-Ruiz, J. Protective effect of melatonin against chlorophyll degradation during the senescence of barley leaves. J. Pineal Res. 2008, 46, 58-63. [CrossRef] [PubMed]

12. Byeon, Y.; Park, S.; Kim, Y.S.; Back, K. Microarray analysis of genes differentially expressed in melatonin-rich transgenic rice expressing a sheep serotonin $\mathrm{N}$-acetyltransferase. J. Pineal Res. 2013, 55, 357-363. [CrossRef]

13. Sarropoulou, V.; Dimassi-Theriou, K.; Therios, I.; Koukourikou-Petridou, M. Melatonin enhances root regeneration, photosynthetic pigments, biomass, total carbohydrates and proline content in the cherry rootstock phl-c (prunus avium $\times$ prunus cerasus). Plant. Physio Bioch. 2012, 61, 162-168. [CrossRef]

14. Szafrańska, K.; Glińska, S.; Janas, K.M. Ameliorative effect of melatonin on meristematic cells of chilled and re-warmed Vigna radiata roots. Biol. Plant. 2013, 57, 91-96. [CrossRef]

15. Wang, P.; Yin, L.; Liang, D.; Li, C.; Ma, F.; Yue, Z. Delayed senescence of apple leaves by exogenous melatonin treatment: Toward regulating the ascorbate-glutathione cycle. J. Pineal Res. 2011, 53, 11-20. [CrossRef]

16. Wang, P.; Sun, X.; Li, C.; Wei, Z.; Liang, D.; Ma, F. Long-term exogenous application of melatonin delays drought-induced leaf senescence in apple. J. Pineal Res. 2012, 54, 292-302. [CrossRef]

17. Weeda, S.; Zhang, N.; Zhao, X.; Ndip, G.; Guo, Y.; Buck, G.A.; Fu, C.; Ren, S. Arabidopsis Transcriptome Analysis Reveals Key Roles of Melatonin in Plant Defense Systems. PLoS ONE 2014, 9, e93462. [CrossRef]

18. Liu, N.; Jin, Z.; Wang, S.; Gong, B.; Wen, D.; Wang, X.; Wei, M.; Shi, Q. Sodic alkaline stress mitigation with exogenous melatonin involves reactive oxygen metabolism and ion homeostasis in tomato. Sci. Hortic. 2015, 181, 18-25. [CrossRef]

19. Turk, H.; Erdal, S.; Genisel, M.; Atici, O.; Demir, Y.; Yanmis, D. The regulatory effect of melatonin on physiological, biochemical and molecular parameters in cold-stressed wheat seedlings. Plant. Growth Regul. 2014, 74, 139-152. [CrossRef] 
20. Wei, W.; Li, Q.; Chu, Y.-N.; Reiter, R.J.; Yu, X.-M.; Zhu, D.-H.; Zhang, W.-K.; Ma, B.; Lin, Q.; Zhang, J.-S.; et al. Melatonin enhances plant growth and abiotic stress tolerance in soybean plants. J. Exp. Bot. 2014, 66, 695-707. [CrossRef]

21. Arnao, M.B.; Ruiz, J.H. Functions of melatonin in plants: A review. J. Pineal Res. 2015, 59, 133-150. [CrossRef] [PubMed]

22. Meng, J.-F.; Xu, T.-F.; Wang, Z.-Z.; Fang, Y.-L.; Xi, Z.-M.; Zhang, Z.-W. The ameliorative effects of exogenous melatonin on grape cuttings under water-deficient stress: Antioxidant metabolites, leaf anatomy, and chloroplast morphology. J. Pineal Res. 2014, 57, 200-212. [CrossRef] [PubMed]

23. Yadu, B.; Chandrakar, V.; Meena, R.K.; Poddar, A.N.; Keshavkant, S. Spermidine and Melatonin Attenuate Fluoride Toxicity by Regulating Gene Expression of Antioxidants in Cajanus cajan L. J. Plant. Growth Regul. 2018, 37, 1113-1126. [CrossRef]

24. Shi, H.; Chen, K.; Wei, Y.; He, C. Fundamental Issues of Melatonin-Mediated Stress Signaling in Plants. Front. Plant. Sci. 2016, 7. [CrossRef] [PubMed]

25. Selvakumar, G.; Kim, K.; Hu, S.; Sa, T. Effect of salinity on plants and the role of arbuscular mycorrhizal fungi and plant growth-promoting rhizobacteria in alleviation of salt stress. In Physiological Mechanisms and Adaptation Strategies in Plants under Changing Environment; Ahmad, P., Wani, M.R., Eds.; Springer: New York, NY, USA, 2013; pp. 115-144. [CrossRef]

26. Rozema, J.; Flowers, T. Crops for a Salinized World. Science 2008, 322, 1478-1480. [CrossRef]

27. Zhou, X.; Zhao, H.; Cao, K.; Hu, L.; Du, T.; Baluška, F.; Zou, Z. Beneficial roles of melatonin on redox regulation of photo-synthetic electron transport and synthesis of D1 protein in tomato seedlings under salt stress. Front. Plant. Sci. 2016, 7. [CrossRef]

28. Alexieva, V.; Sergiev, I.; Mapelli, S.; Karanov, E. The effect of drought and ultraviolet radiation on growth and stress markers in pea and wheat. Plant. Cell Environ. 2001, 24, 1337-1344. [CrossRef]

29. Bajji, M.; Bertin, P.; Lutts, S.; Kinet, J.M. Evaluation of drought resistance-related traits in durum wheat somaclonal lines se-lected in vitro. Anim Prod. Sci. 2004, 44, 27-35. [CrossRef]

30. Beyer, W.F., Jr.; Fridovich, I. Assaying for superoxide dismutase activity: Some large consequences of minor changes in conditions. Anal. Biochem. 1987, 161, 559-566. [CrossRef]

31. Muñoz-Muñoz, J.; García-Molina, F.; García-Ruiz, P.; Arribas, E.; Tudela, J.; García-Cánovas, F.; Rodríguez-López, J. Enzymatic and chemical oxidation of trihydroxylated phenols. Food Chem. 2009, 113, 435-444. [CrossRef]

32. Aebi, H. Methods in enzymology. Catalase Vitro 1984, 105, 121-126. [CrossRef]

33. Nakano, Y.; Asada, K. Hydrogen Peroxide is Scavenged by Ascorbate-specific Peroxidase in Spinach Chloroplasts. Plant Cell Physiol. 1981, 22, 867-880. [CrossRef]

34. Zhu, H.; Cao, Z.; Zhang, L.; Trush, M.A.; Li, Y. Glutathione and glutathione-linked enzymes in normal human aortic smooth muscle cells: Chemical inducibility and protection against reactive oxygen and nitrogen species-induced injury. Mol. Cell. Biochem. 2007, 301, 47-59. [CrossRef]

35. Zhang, J.; Kirkham, M.B. Antioxidant responses to drought in sunflower and sorghum seedlings. New Phytol. 1996, 132, 361-373. [CrossRef]

36. Nagalakshmi, N.; Prasad, M. Responses of glutathione cycle enzymes and glutathione metabolism to copper stress in Scenedesmus bijugatus. Plant. Sci. 2001, 160, 291-299. [CrossRef]

37. Arnon, D.I. Copper enzymes in isolated chloroplasts. Polyphenoloxidase in Beta vulgaris. Plant. Physiol. 1949, 24, 1-15. [CrossRef]

38. Chartzoulakis, K.; Klapaki, G. Response of two greenhouse pepper hybrids to $\mathrm{NaCl}$ salinity during different growth stages. Sci. Hortic. 2000, 86, 247-260. [CrossRef]

39. Cuartero, J.; Bolarin, M.C.; Asins, M.; Moreno, V. Increasing salt tolerance in the tomato. J. Exp. Bot. 2006, 57, 1045-1058. [CrossRef] [PubMed]

40. Zhu, J.-K. Salt and Drought Stress Signal Transduction in Plants. Annu. Rev. Plant. Biol. 2002, 53, 247-273. [CrossRef]

41. Wang, L.Y.; Liu, J.L.; Wang, W.X.; Sun, Y. Exogenous melatonin improves growth and photosynthetic capacity of cucumber under salinity-induced stress. Photosynthetica 2016, 54, 19-27. [CrossRef]

42. Chaves, M.M.; Flexas, J.; Pinheiro, C. Photosynthesis under drought and salt stress: Regulation mechanisms from whole plant to cell. Ann. Bot. 2009, 103, 551-560. [CrossRef] [PubMed]

43. Von Caemmerer, S.; Farquhar, G.D. Some relationships between the biochemistry of photosynthesis and the gas exchange of leaves. Planta 1981, 153, 376-387. [CrossRef] [PubMed]

44. Li, C.; Tan, D.-X.; Liang, D.; Chang, C.; Jia, D.; Ma, F. Melatonin mediates the regulation of ABA metabolism, free-radical scavenging, and stomatal behaviour in two Malus species under drought stress. J. Exp. Bot. 2014, 66, 669-680. [CrossRef] [PubMed] 